\author{
大画面立体ディスプレイ用 \\ ハイブリッド・ホログラム・スクリーンの開発
}

宋玄鎬 ****, 渋谷岳人 *, 本田捷夫*

*千葉大学 自然科学研究科 (

**市立仁川専門大学 ( $4402-750$ 韓国仁川市南区道禾洞235)

\title{
Development of Hybrid Hologram Screen for Large Auto-Stereoscopic Display
}

\author{
Hyun Ho SONG,*,** Taketo SHIBUYA,* and Toshio HONDA* \\ *Graduate School of Science and Technology, Chiba University 1-33 Yayoi-cho, Inage-ku, Chiba 263-8522 \\ **Incheon city college 235 Dowhadong, Manku, Incheon, 402-750 Korea
}

(Received August 15, 2002)

\begin{abstract}
Hologram screen for auto-stereoscopic 3-D display has the merit that the size of viewing zone can be controlled adequately. But it has fundamentally color dispersion and color aberration when the hologram screen is illuminated by white light. Therefore, it is required that little color dispersion and little color aberration is realized. In this paper, we propose the hologram screen attached with Fresnel lens, and the effect of the screen is demonstrated by simulation and by a experiment.
\end{abstract}

Key Words: Auto stereoscopic display, Hologram screen, Viewing zone, Color dispersion, Color aberration

1.はじめに

レーザー光は単色性, 指向性, 干渉性が良い特徴を持 つコヒーレントな光である.コヒーレントな光を用いて 光波面そのものを記録・再生することにより理想的な立 体像が表示できるホログラムでは，記録時にレーザーが 使われる。ホログラムによる映画の試みはあるが，大部 分は静止立体像表示に限られている。

一方，動画立体像表示技術の1つとして立体像をスク リーンに投写する方式がある。この方式で現在実用化さ れている方式はすべて, 観察時に特殊なメガネを装着す る必要があるが, 裸眼で立体像が観察できる方式も研究 開発されている。裸眼で観察できる方式にはレンチキュ ラースクリーンを用いる方式，パララックス・バリア方 式，凸レンズ方式，ホログラム・スクリーンを用いる方 式がある11.

Fig. 1に凸レンズを用いる方式を示す.この方式の原理 は, 少し離れた $2 つ の$ 光源の像を凸レンズにより, 観察者 の左右の眼の位置にのみ集光させ，それと同時に，それ ぞれの眼に入る (光の) 像に視差を持たせる.この方式は観 察者が 1 人に限定され，しかも視域が狭い。この方式で視 域を広くするためは視点追従が不可欠である.

左右それぞれの眼で視差画像が同時に観察でき, 立体 像が見える観察者の眼の位置範囲を「視域」と呼ぶ。この視 域が広いことが立体ディスプレイには重要である。 視域が広くなれば観察者は自由な姿勢で立体映像を見る
ことが可能になる。また，高臨場感ディスプレイのため には，表示・観察される立体像が大きいことも重要であ る、スクリーンに投影して見せるタイプの立体像表示シ ステムでは，立体像が大きいことは，大きいスクリーン を意味する。広視域化やスクリーンの大型化を実現でき る方式の1つとしてホログラム・スクリーンがある2,3).

本論文はハイブリッド・ホログラム・スクリーンを用 いることによりホログラム・スクリーンで問題であった 狭い視域を広く改善すると共にスクリーンの大型化でき る方式に関する。

\section{2. ホログラム・スクリーンの特徴と問題点}

2眼立体像表示用ホログラム・スクリーンは前記視域の 大きさを任意に調節できることが唯一最大の特徵である。

ホログラム・スクリーンの従来作成法として収束する

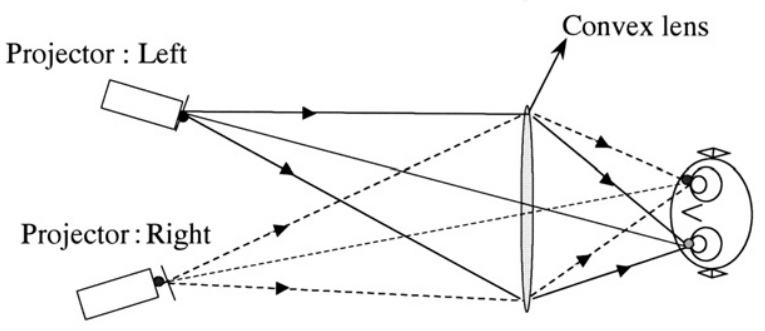

Fig. 1 Auto-stereoscopic display by a convex lens. 
球面参照光を用いた場合の記録光学系をFig. 2に示す. ス クリーンとしての使用時にはFig. 3(a)で示すように記録時 の収束する点(Fig. 2のD点に該当)にプロジェクターの投影 レンズを置き, そこから広がる光線束でホログラム・ス クリーンを照明する。

ホログラム・スクリーンはFig. 3(a)，（b)に示すように 特定方向から入射した光を決められた方向範囲へのみ回 折させる指向性の機能を持つ。すなわち，このような照 明により，ホログラム・スクリーンからの+1次回折光 は，観察者の眼の位置に記録時拡散板の実像を生じる. この実像の大きさが視域の大きさになる。

再生光源は2台のプロジェク夕ーでありホログラム・ス クリーンへ視差画像を投影し左右それぞれの目が視差画 像を見て立体視を行う。この特徵はホログラム・スク リーン自体を大型化しても維持されるので，スクリーン の大型化に有利である.

しかし，プロジェクターは白色光であり，斜め下ある いは上から照明するので, 大きい色分散および色収差が 生じてしまう。この現象は，スクリーンサイズが大きく

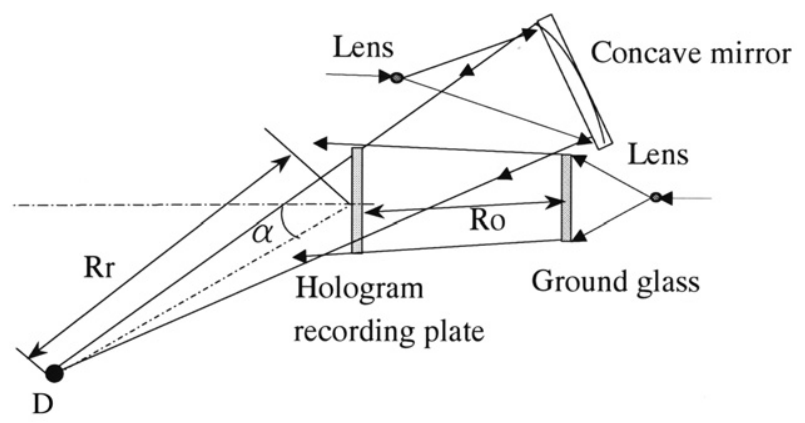

Fig. 2 Recording of the holographic screen by converging reference wave, and real image reconstruction of viewing-zone (side view).

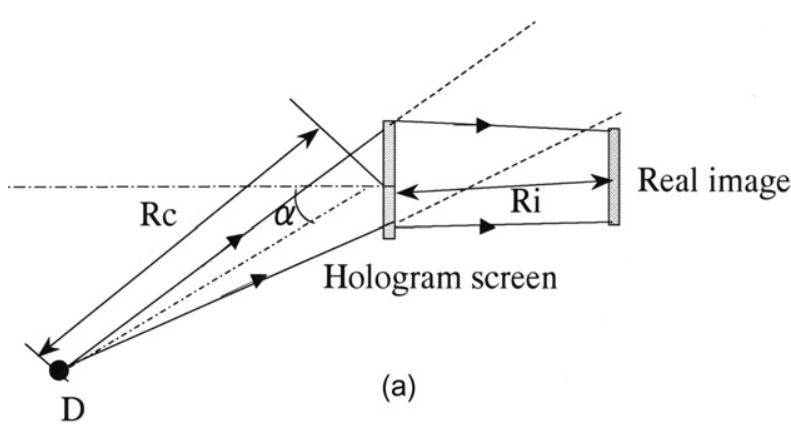

Projector: Left

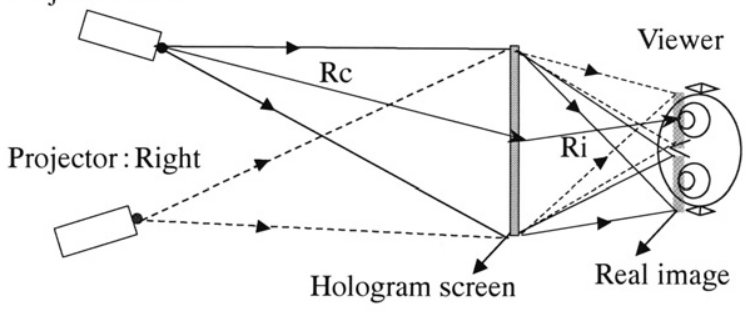

(b) Top view

Fig. 3 Use (Reconstruction) of the holographic screen of Fig. 2 (a)Side view, (b) Top view.
なる場合に顕著に現れ，スクリーンの大型化が原理的に 困難になる。また，現実的問題として，スクリーンサイ ズを大型にしょうとすると, それより大きい有効径の大 きい凹面鏡が必要になる。

\section{3. 大型ホログラム・スクリーンにおける色収差}

白色光であるプロジェクターでホログラム・スクリー ンを照明すると記録時と再生時の光源の条件が一致しな いため, 再生時に色分散と色収差が必ず起こる。特にス クリーンサイズが大きくなると色分散と色収差量も大き くなることが予測される。

この色分散・収差量がどの程度になるかをホログラム の結像公式4)を用いて回折光線の方向を計算し観察面での スポットダイアグラム5)によりホログラム・スクリーンで の視域がどうなるかを数值計算した.

ホログラムの結像公式とは式(1)〜式(3)に示される関係式 である。

これらの式の中で, それぞれの記号は, 次のとおりで ある. $\lambda_{\mathrm{R}}$ : 記録波長, $\lambda_{\mathrm{C}}$ : 再生波長, $\mathrm{R}_{0}$ : 物体光点とホ ログラム・スクリーン面までの距離, $\mathrm{R}_{\mathrm{r}}$ : 参照光点とホロ グラム・スクリーン面までの距離, $\mathrm{R}_{\mathrm{C}}$ ：再生用照明光点 とホログラム・スクリーンまでの距離, $\mathrm{R}_{\mathrm{i}}$ ：ホログラム スクリーンから近軸像点までの距離。 それから添字 $\mathrm{o}, \mathrm{r}$, cはそれぞれ物体光, 参照光, 再生照明光の各点光源を意 味する. 長さについては, Fig. 2とFig. 3に示している. 数值計算の物体 (光)の条件として,

$$
\begin{aligned}
& \frac{1}{\lambda_{c}}\left(\frac{1}{R_{i}}-\frac{1}{R_{c}}\right)=\frac{1}{\lambda_{R}}\left(\frac{1}{R_{o}}-\frac{1}{R_{r}}\right) \\
& \frac{1}{\lambda_{c}}\left(\frac{X_{i}}{R_{i}}-\frac{X_{c}}{R_{c}}\right)=\frac{1}{\lambda_{R}}\left(\frac{X_{o}}{R_{o}}-\frac{X_{r}}{R_{r}}\right) \\
& \frac{1}{\lambda_{c}}\left(\frac{Y_{i}}{R_{i}}-\frac{Y_{c}}{R_{c}}\right)=\frac{1}{\lambda_{R}}\left(\frac{Y_{o}}{R_{o}}-\frac{Y_{r}}{R_{r}}\right)
\end{aligned}
$$

(1) 高さ125 mmの線状の拡散面

(2) $60 \mathrm{~mm}(\mathrm{H}) \times 125 \mathrm{~mm}(\mathrm{~V})$ の拡散面 その他の条件は同じで，以下に示す.

記録時：

参照光：収束する球面波で, ホログラム面の法線方向と 35度の角で斜め下方向

$$
\text { 記録レーザー光の波長 : } 532 \mathrm{~nm}
$$$$
\text { ホログラムサイズ(スクリーンサイズ }): 17 \operatorname{inch~}(\mathrm{H}) \times 13
$$
$\operatorname{inch}(\mathrm{V})$

再生時:

照明光：記録時参照光の収束点から発散し，記録時と 逆方向に進む球面波(共役光波面という)による実像再生 なお，再生照明光は白色光であるが，計算では記録時と 同じ532 nm(緑色)の波長の光, $450 \mathrm{~nm}$ の波長の光(青色), $650 \mathrm{~nm}$ の光(赤色) を再生波長として計算を行った.

また，再生時には，Fig. 3(b)に示すように2台のプロ ジェクターをオフアクシスで用いるが，計算では，2台の 
中間に1台のプロジェクターを置いて再生した場合を想定 している.

上記の条件のもとで, 記録時の拡散物体面の線状, あ るいは矩形形状が，記録時の拡散物体面 (立体像観察面)に おいて，再生時にそれぞれどのような位置・形状に再生 されるかを計算した。物体として60 mm $(\mathrm{H}) \times 125 \mathrm{~mm}(\mathrm{~V})$ の拡散面を用いた時の記録時の様子を，Fig. 4に示す。

計算した, 一種のスポットダイアグラムの結果を, 物 体を(1)高さ $125 \mathrm{~mm}$ の線状の拡散面とした場合については Fig. 5, 物体を(2)60 mm (H) × $125 \mathrm{~mm}(\mathrm{~V})$ の拡散面にした 場合についてはFig. 6に示す.

Fig. 5, Fig.6よりわかるように, $532 \mathrm{~nm}$ の波長では, ホ ログラム・スクリーンから回折される光線は, 記録時の 拡散面(スリガラス) と同じ線状, あるいは矩形を, 記録時 の拡散物体の位置と同じ位置に形成する。一方, 450 $\mathrm{nm}, 650 \mathrm{~nm}$ の波長の光は, それぞれ大きさと形状が変 わった矩形を形成する。

このように, 収束する球面参照光を用いてホログラム を記録し, 共役光により実像再生を行う場合は, ホログ ラム・スクリーンから回折した光線が同じ位置に集まら ず，観察面において垂直・水平方向へ大きな横収差を持 つ、その結果, 水平方向視域幅を $60 \mathrm{~mm}$ に制限することが できず，このスクリーンでは 2 眼式オートステレオスコ ピック・ディスプレイを実現できない.

\section{4. 色収差を小さくするハイブリッド ホログラム・スクリーン}

2眼式で立体視を行う際に立体像が見える観察範囲であ る視域として, 水平方向については約 $60 \mathrm{~mm}$ (ほぼ両眼の 間隔)で，白色・均一明るさでスクリーンが見えることが 不可欠である。これを実現するためには, 前述の色分 散・色収差の影響を相当小さくすることが重要である. そのためには, 参照光の角度を小さくすることが基本的 である。しかし，再生時の照明角度を浅くして再生を行 うと，ホログラム・スクリーンからは回折しない 0 次光が 観察者の目に入ってしまい, 投影像の観察に邪魔にな る。これを避けることが不可欠である。

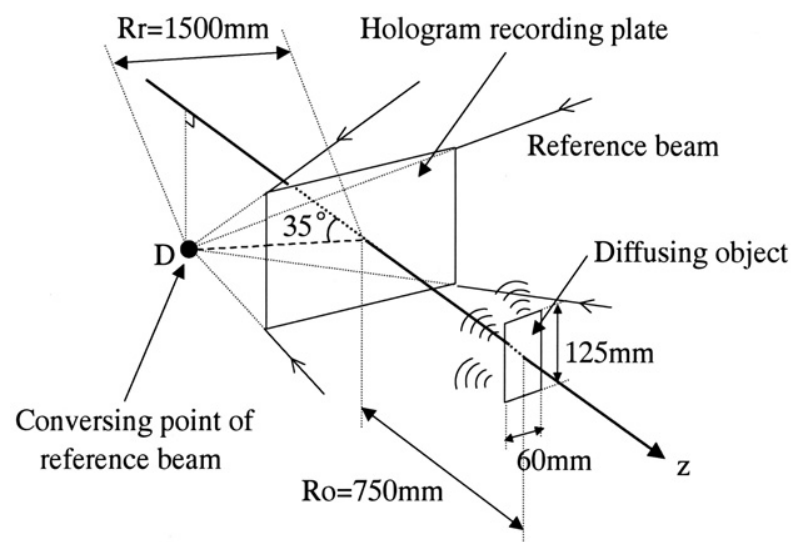

Fig. 4 Optical set-up of recording the holographic screen of Fig. 2 for the simulation.

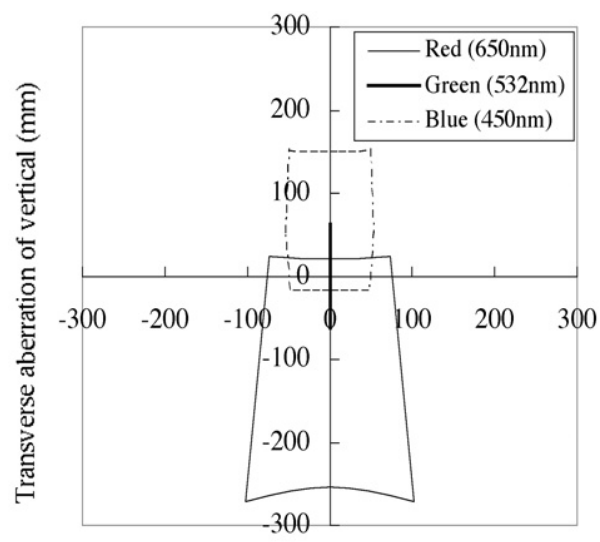

Transverse aberration of horizontal $(\mathrm{mm})$

Fig. 5 Reconstructed image areas of vertical diffuse line object at the viewing-zone plane by three different wavelength light.

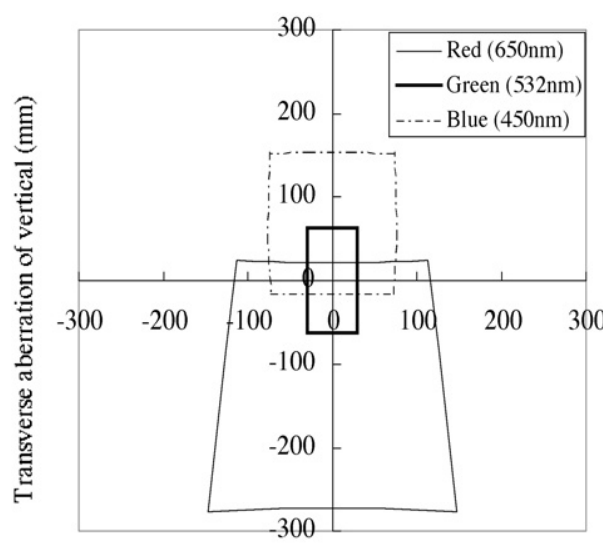

Transverse aberration of horizontal $(\mathrm{mm})$

Fig. 6 Reconstructed image areas of squared diffuse object at the viewing-zone plane by three different wavelength light.

それを避けることができる可能性がある一つの方法と して，ホログラム・スクリーンとしての使用時に，その スクリーンにフレネルレンズを合わせて使用する方式を 提案する. そうすると, 参照光角度を浅くしても, 0 次光 を実像に変換することになり, 観察者の目に入る0次光を 避けることができる.

記録方式は Fig. 7に示すように，参照光角度を浅くし， また参照光波面として, 発散する球面波とする。この記録 方式だと, 大きいホログラム・スクリーンの記録にも, Fig. 2に示すような, 大きい凹面鏡を使う必要はない. このホログラム・スクリーンを照明(再生)する場合は, Fig. 8(a)に示すように，プロジェクターの投影レンズの位 置 ·距離(再生光源の位置 - 距離, Fig. 7のLに該当)の関係 が記録時の参照光と同じとし，ホログラム・スクリーン からの虚像を再生する。

フレネルレンズはまた，照明時(再生時)の虚像である 拡散物体を実像に変換する働きも持たせている.

このように, 参照光の入射角度は光軸に対し浅くなれば 観察時に生じる色分散・色収差が低減されると予想され る. 


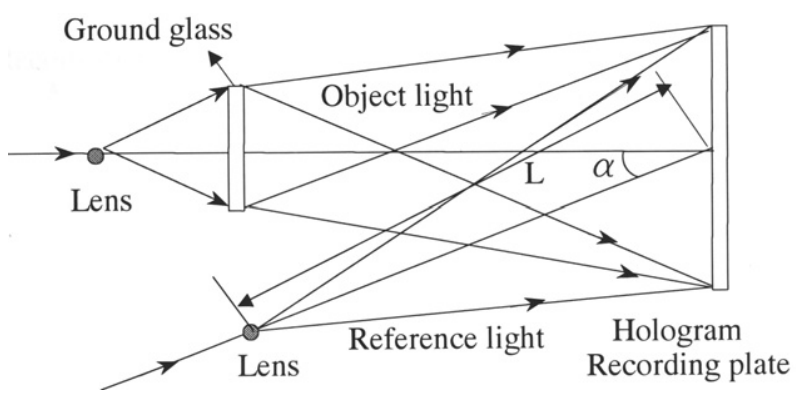

Fig. 7 Recording of the holographic screen by diverging reference wave, and virtual image reconstruction of viewing-zone (side view).

フレネルレンズとホログラム・スクリーンを合わせた 1 つのスクリーンをここではハイブリッド・ホログラムス クリーンと呼ぶ.

このようにしてハイブリッドホログラム・スクリーンを 用いた2眼式立体像再生システムの概念図をFig. 8(a)，（b) に示す。この場合に観察面で視域がどのようになるか を, 数值計算例として, 以下に示す.

ホログラム・スクリーンを記録するとき, 参照光は球面 発散光とし, 角度 $\alpha$ を 15 度, 物体光は拡散面光源として $250 \mathrm{~mm}(\mathrm{~V}) \times 120 \mathrm{~mm}(\mathrm{H})$, 記録感光材料の中心までの距 離は物体光と参照光共に $1500 \mathrm{~mm}$ とする。前節の場合と同 じように, 再生光の観察面での拡散面の再生像の広がり を, $450 \mathrm{~nm}, 532 \mathrm{~nm}$ (ホログラム記録時の波長), $650 \mathrm{~nm}$ のそれぞれの波長について, 求めた結果をFig. 9に示す. この計算では, フレネルレンズは, $1,500 \mathrm{~mm}$ の拡散物体 を, 無収差で750 mm の位置に実像結像すると仮定してい る.

Fig. 9の結果はFig. 5, Fig. 6と比べると, どの波長に対 しても, 水平方向視域の広がりが小さく, ほぼ所定の範 囲に収まっていることがわかる。

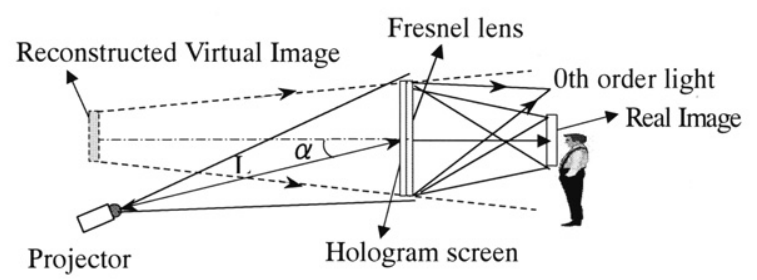

(a) Side view

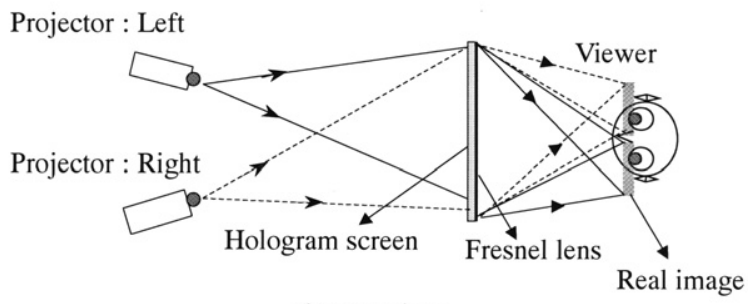

(b) Top view

Fig. 8 Use (reconstruction) of the holographic screen of Fig. 7 attached with a Fresnel lens (hybrid hologram screen) assumed at the simulation and the experiment (a) Side view, (b) Top view.

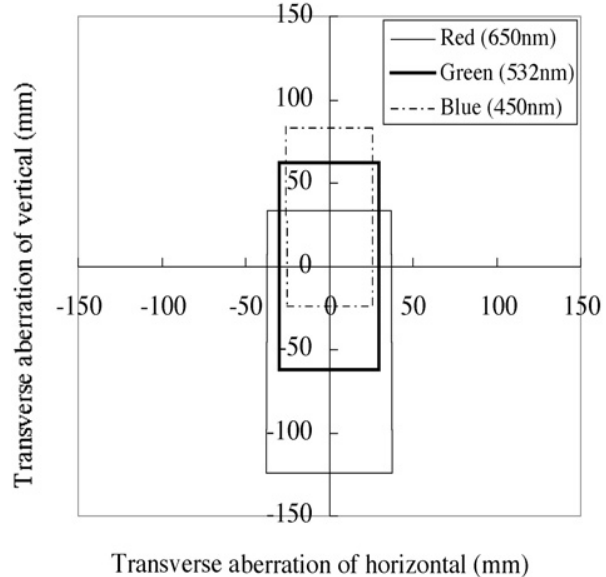

Fig. 9 Reconstructed image areas of squared diffuse object at the viewing-zone plane by three different wavelength light (simulation).

Fig. 9に示すように, 再生時に色分散から白色に見える垂 直方向視域は $55.75 \mathrm{~mm}$ であり，水平視域の幅は60 mmであ る.

\section{5. 実 験}

ホログラム・スクリーンを作成するための記録条件は シミュレーションと同じである。記録波長は5 $32 \mathrm{~nm}$ の SHG laser，ホログラム記録感光材料としては17 inch $(\mathrm{H}) \times$ 13 inch (V)のコニカ (株) 製P5600を用いた。拡散物体とし てはスリガラスを用いた。

現像処理はMA現像液とEDTA漂白を経て自然乾燥し た。

作成した $17 \times 13$ inchのホログラム・スクリーンと焦点 距離500 mmのフレネルレンズを合わせてFig. 8に示す再生 光学系を用いて再生を行った。結果としてホログラム． スクリーンから $750 \mathrm{~mm}$ 離れた位置である観察面で設定し たとおりの $60 \mathrm{~mm}$ の水平視域を得ることができた.

このハイブリッド・ホログラムスクリーンをプロジェ クター2台で白色照明し, 観察面に紙を置いてその面を写 真撮影した結果をFig. 10に示す.

この図で, Whiteで示されている囲まれた範囲内に左眼

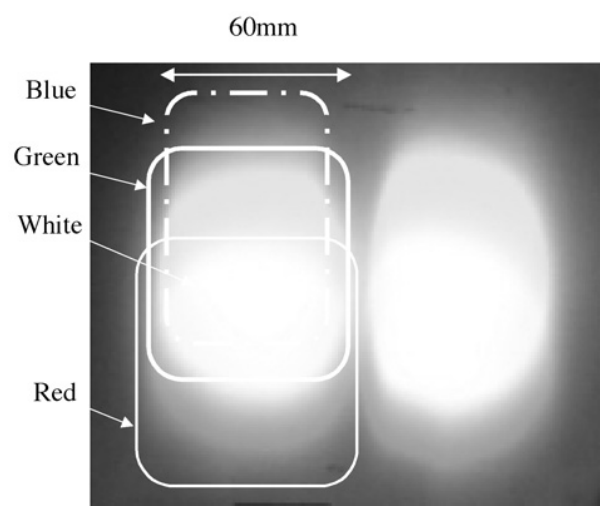

Fig. 10 Reconstructed light intensity distributions in the experiment of the same condition of Fig. 9 (photograph by the illumination of two projectors, Color areas are surrounded by three circles ). 
(右の部分については右眼)を置けば，カラー立体像が観察 できる. 観察される立体像の一例をFig. 11に示す。この像 は, Fig. 10のWhite部左右に撮像カメラを置き, スクリー ン面を撮った写真である. カメラレンズ位置に両眼を置 けば，立方体の立体像が明確に観察できる。

白色に見える垂直方向視域は, 計算では前述のように 約 $55.75 \mathrm{~mm}$ でるが, 実際には約 $30 \mathrm{~mm}$ と, 計算結果と比 ベて狭くなった。この理由は, 記録時にスリガラスの上 下の部分からの散乱光強度が弱く, 完全拡散面でなかっ たことによる。

$$
\text { 6. まとめ }
$$

本報告では広視域の状態で 2 眼式オートステレオスコ ピック・デイスプレイが可能なハイブリッド・ホログラ ム・スクリーンの作成を実現した。記録時は光軸に対し て参照光の入射角度を 15 度と小さく設定することによ り，観察の際に色収差の影響を低減化できた。再生入射 角度が浅くなったときに生じる0次光が観察者の眼に入る 問題は，フレネルレンズを合わせて使うことにより解決 した。

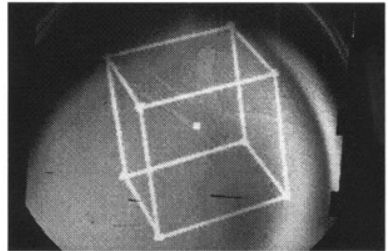

(a) Left

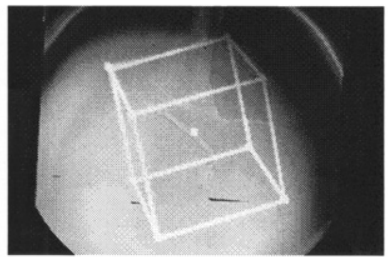

(b) Right
Fig. 11 Images observed at the view-zone of right and left eye of Fig. 10, respectively (The photographs were taken by a camera positioned at the respective viewzone).

\section{参考文献}

1) 岡野 文男: 光学 31 (2002) 40.

2) C. Newswanger: US Patent, WO4799739 (1989).

3) M. R. Shires: US Patent, WO5521724 (1996).

4) E. B. Champagne: Opt. Soc. Am. 57 (1967) 51.

5) J. F. Miles: Opt. Acta 20 (1973) 19. 